\title{
INFLUENCE OF TA CONTENT IN HIGH PURITY NIOBIUM ON CAVITY PERFORMANCE*
}

\author{
P. Kneisel", G. Ciovati, G. R. Myneni, TJNAF, Newport News, VA 23606, USA \\ W.Singer, X. Singer, D. Proch, DESY, 22603 Hamburg, Germany \\ T. Carneiro, Reference Metals Co., Bridgeville, PA, USA.
}

\section{Abstract}

In a previous paper [1] we have reported about initial tests of single cell $1500 \mathrm{MHz}$ cavities made from high purity niobium with three different Ta contents of 160 ppm , $600 \mathrm{ppm}$ and $\sim 1400 \mathrm{ppm}$. These cavities had been treated by buffered chemical polishing several times and $100 \mu \mathrm{m}, 200 \mu \mathrm{m}$ and $300 \mu \mathrm{m}$ of material had been removed from the surfaces. This contribution reports about subsequent tests following post purification heat treatments with $\mathrm{Ti}$ and "in situ" baking. As a result, all cavities exhibited increased quench fields due to the improved thermal conductivity after the heat treatment. After the "in situ" baking at $120{ }^{\circ} \mathrm{C}$ for $\sim 40 \mathrm{hrs}$ the always present Q-drop at high fields disappeared and further improvements in accelerating gradient could be realized. Gradients as high as $\mathrm{E}_{\mathrm{acc}}=35 \mathrm{MV} / \mathrm{m}$ were achieved and there were no clear indications that the cavity performance was influenced by the Ta content in the material. A multi-cell cavity from the high Ta content material has been fabricated and initial results are reported.

\section{INTRODUCTION}

The main information from the previous paper are shortly summarized as following:

Four niobium ingots with different Ta contents $(<150$ wtppm, $\sim 600$ wtppm, $\sim 1200$ wtppm and $\sim 1300$ wtppm) were fabricated by CBMM from the pyrochlore deposits in Araxa, Brasil. Standard processing procedures [2] converted the ore to niobium ingots after triple electron beam melting of aluminothermically reduced niobium oxide. Addition of different amounts of Ta (See Ref. [1]) produced the four different ingots; the content of other interstitial impurities was kept the same and verified by chemical analysis. The ingots were converted into $2.8 \mathrm{~mm}$ thick sheets at the Tokyo Denkai facility in Japan in accordance with their standard processing procedures [3]. The RRR-values of sheets with different Ta content were measured on samples before and after a post-purification vacuum heat treatment at $1400{ }^{\circ} \mathrm{C}$ for $3 \mathrm{hrs}$ (Table 1). As expected, the post-purification heat treatment increased RRR, however, because of the relatively low interstitial impurity content, the improvement remained modest.

QA steps such as thermal conductivity measurements of ingots and rolled sheets and evaluation of mechanical properties of the rolled sheets accompanied production. All sheets were scanned for defects and/or Ta clusters by means of an eddy current system.

\footnotetext{
*Supported in part by DOE contract DE-AC05-84ER40150

${ }^{*}$ kneisel@jlab.org
}

Table 1: Residual Resistivity Ratios for different

Ta contents for ingot and sheet

\begin{tabular}{|l|l|l|l|}
\hline $\begin{array}{l}\text { Ta content } \\
\text { Sheet } \#\end{array}$ & RRR ingot & RRR sheet & $\begin{array}{l}\text { RRR sheet } \\
\text { heated }\end{array}$ \\
\hline $\begin{array}{l}150 \mathrm{ppm} \\
1161\end{array}$ & 180 & 178 & 323 \\
\hline $\begin{array}{l}\sim 600 \mathrm{ppm} \\
1162\end{array}$ & 170 & 231 & 345 \\
\hline $\begin{array}{l}\sim 1200 \mathrm{ppm} \\
1163\end{array}$ & 150 & 177 & 266 \\
\hline $\begin{array}{l}1300 \mathrm{ppm} \\
1164\end{array}$ & 150 & 168 & 240 \\
\hline
\end{tabular}

Two single cell cavities each were manufactured from the material with $\sim 160$ wtppm , 600 wtppm and $\sim 1300$ wtppm. Each cavity was tested three times at $2 \mathrm{~K}\left(\mathrm{Q}_{0}\right.$ vs $\left.E_{a c c}\right)$ with the following results after the removal of $100 \mu \mathrm{m}, 200 \mu \mathrm{m}$ and $300 \mu \mathrm{m}$ :

- All cavities "quenched" at the field levels indicated in Table 2; no field emission was observed. No improvement in performance with additional material removal was observed.

- All cavities showed a strong Q-drop at gradients $\mathrm{E}_{\mathrm{acc}}>\sim 20 \mathrm{MV} / \mathrm{m}$

- No significant differences in performances for 150 wtppm $<\mathrm{Ta}<1300$ wtppm was found

- One cavity of each Ta content was heat treated in vacuum at $800{ }^{\circ} \mathrm{C}$ for $6 \mathrm{hrs}$ in a Ti box. No improvement in quench fields was observed after removal of an additional $100 \mu \mathrm{m}$ of material.

\section{RF TESTING}

\section{Single Cell Cavities}

After the series of tests summarized above, all 6 single cell cavities were subjected to the following additional treatments. The cavities were post-purified in the presence of $\mathrm{Ti}$ as a solid state getter material at a temperature of $1250{ }^{\circ} \mathrm{C}$ (the limitation of our UHV furnace at JLab) for $12 \mathrm{hrs}$ and subsequently held at $1000{ }^{\circ} \mathrm{C}$ for an additional $24 \mathrm{hrs}$ prior to cooldown to room temperature. A chemical surface treatment with a buffered acid mixture of equal parts of nitric, hydrofluoric and phosphoric acids was applied, removing approximately $100 \mu \mathrm{m}$ of material from the surface. Subsequently the cavities were high pressure rinsed for $30 \mathrm{~min}$, dried for $2 \mathrm{hrs}$ in a class 10 
clean room prior to assembly of the rf input - and output coupling probes and evacuation on the test stand. After $12 \mathrm{hrs}$ on the test stand the cavity vacuum had improved to the low $10^{-8}$ mbar range, and the cavity was cooled down to liquid helium temperature.

The subsequent $\mathrm{rf}$ tests consisted of measuring the surface resistance between $4.2 \mathrm{~K}$ and $2 \mathrm{~K}$ and the dependence of the Q-value on accelerating gradient ( $\mathrm{Q}$ vs. $\mathrm{E}_{\mathrm{acc}}$ ) at $2 \mathrm{~K}$.

A second set of measurements was done after "in situ" baking of the cavities at a temperature of $120^{\circ} \mathrm{C}$ for $40-$ $48 \mathrm{hrs}$, conditions, which had been optimized by one of the authors [4].

\section{Seven Cell Cavity}

In addition to the single cell cavities a 7-cell cavity of the high gradient (HG) type was fabricated from the material with the highest Ta contents, using standard fabrication techniques: half cells were deep drawn, machined to dimension with a self centering welding recess and combined into "dumbbells". After mechanical polishing to remove any surface imperfections and a removal of app. $30 \mu \mathrm{m}$ from the surface by Buffered Chemical Polishing (BCP) the dumbbells were assembled together with beam pipe/flange sub-assemblies onto an electron beam welding fixture and welded at the equators during a single pump down of the vacuum chamber. Unfortunately, two of the equator welds developed small hole and had to be re-welded with RRR niobium "patch" material.

Subsequently the cavity was tuned, $100 \mu \mathrm{m}$ of material was removed by BCP 1:1:2 and the cavity was hydrogen degassed at $600{ }^{\circ} \mathrm{C}$ for $10 \mathrm{hrs}$.

\section{RESULTS AND DISCUSSION}

\section{Single Cell Cavities}

The observations from these 12 additional tests can be summarized as following:

- The performance of all cavities improved after the post-purification heat treatment. This is most likely due to the improvement - even though modest - of the thermal conductivity. However, all cavities quenched at the highest gradients.

- All cavities showed the "Q - drop", but compared to the results before the heat treatment, the onset of the Q-degradation had shifted to higher gradients/ magnetic surface fields.

- After "in - situ" baking the "Q-drop" disappeared in all but one case and in some tests the gradient performance of the cavities improved (Figs. 1,2).

- There is no obvious dependence of cavity performance on the Ta contents.

- In some cases residual resistances as low as $2 \mathrm{n} \Omega$ were measured (Fig. 3)

- Energy gap value $\Delta / \mathrm{kT}_{\mathrm{c}}$ ranged between 1.72 and 1.9; after the baking the gap values increased somewhat.

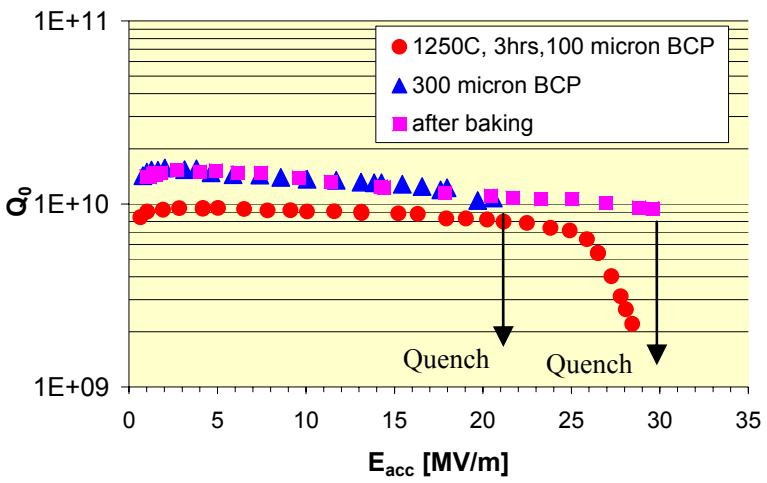

Figure 1: Performance of cavity made from high Ta contents niobium (1300 wtppm). Shown is Q vs. $E_{\text {acc }}$ before heat treatment, after heat treatment and "in situ" baking. $\mathrm{B}_{\mathrm{p}} / \mathrm{E}_{\mathrm{acc}}=4.43 \mathrm{mT} /(\mathrm{MV} / \mathrm{m}), \mathrm{E}_{\mathrm{p}} / \mathrm{E}_{\mathrm{acc}}=1.78$.

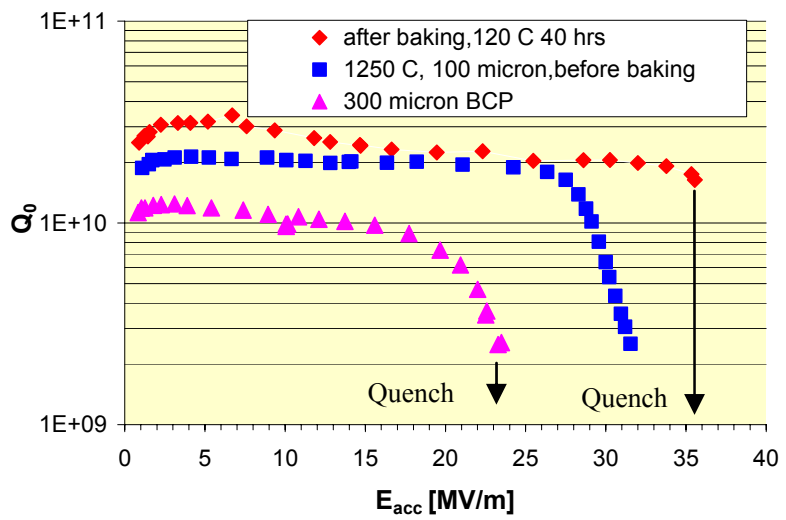

Figure 2: Best performance of all cavities (Ta 600 wtppm).

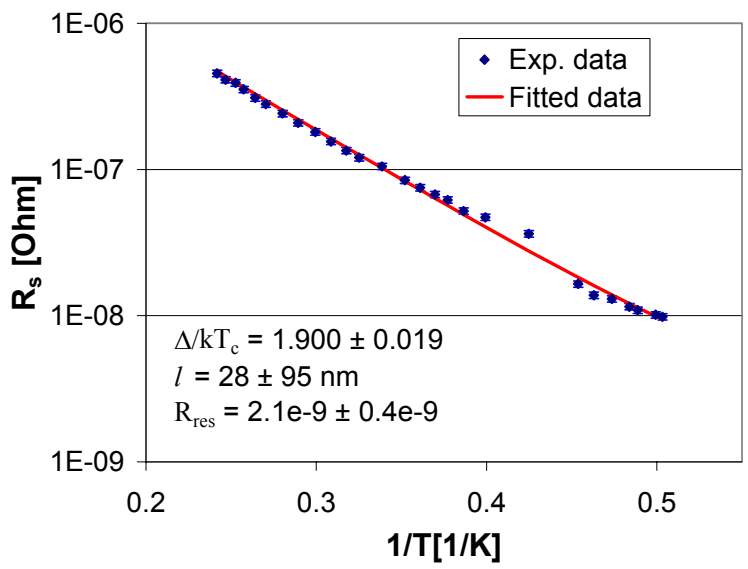

Figure 3: Temperature dependence of surface resistance measured on the cavity of Fig. 2 after "in situ" baking. The data have been compared with the BCS theory and a residual resistance of $\sim 2 \mathrm{n} \Omega$ and a gap value of $\Delta / \mathrm{kT}_{\mathrm{c}}=$ 1.9 was obtained.

\section{Seven Cell Cavity}

After the hydrogen degassing the cavity was retuned and $100 \mu \mathrm{m}$ of material was removed from the surface by BCP 1:1:2. High pressure rinsing in two passes of $2 \mathrm{hrs}$ 
each followed prior to drying of the cavity in the class 10 clean room for approximately $12 \mathrm{hrs}$. Subsequently, rf input - and output coupling probes were attached and the cavity was evacuated on the test stand prior to cooldown to LHe temperatures.

However, the performance of the cavity was disappointing: the cavity had field emission and quenched at an accelerating gradient of $E_{a c c}=15 \mathrm{MV} / \mathrm{m}$. We suspect that this early quench is caused by the repair of the holes and that a performance improvement can be achieved by rework of the repaired areas.

\section{SUMMARY}

The systematic investigations of the effect of Ta contents in high purity $\mathrm{Nb}$ on cavity performance as reported in [1] was continued by subjecting the cavities to post purification heat treatments and "in situ" baking. As summarized in Table 2, which lists for comparison also the results of the previous investigation, in some cases significant improvements in accelerating gradients were obtained. The onset of the "Q-drop" had shifted to higher values and after "in-situ" baking it disappeared altogether.
No systematic dependence of quench field level on Ta contents was seen for $160 \mathrm{wtppm} .<\mathrm{Ta}<1300 \mathrm{wtppm}$.

The achieved accelerating gradients of $>27 \mathrm{MV} / \mathrm{m}$ (corresponding to $\mathrm{B}_{\mathrm{p}}>120 \mathrm{mT}$ ) are not yet acceptable for an accelerator such as the ILC; however less demanding requirements for e.g. RIA, SNS, CEBAF Upgrade, the X-ray FEL or ERLs can be accommodated.

\section{ACKNOWLEDGEMENTS}

We would like to thank our colleagues from Jefferson Lab - Larry Turlington, Robert Manus, Gary Slack, D. Forehand, I. Daniels and Peter Kushnick - for their support of this work.

\section{REFERENCES}

[1] P.Kneisel et al. ; Proc. Linac 2004

[2] H.R. Salles Moura, "Melting and Purification of Niobium", Proc. Intern. Symposium Niobium 2001, Dec. 2-5, 2001, Orlando, FL, p. 147.

[3] H. Umezawa, "Impurity Analysis of High Purity Niobium in Industrial Production", Materiaux \& Techniques, Vol. 7-9, (2003) 33.

[4] G. Ciovati, J. Appl. Phys. 96 No. 3 (2004) 1591.

Table 2: Summary of cavity tests.

\begin{tabular}{|c|c|c|c|c|c|}
\hline $\begin{array}{l}\text { Material \# } \\
\text { Sheet \# }\end{array}$ & $\begin{array}{l}\text { Ta content } \\
\text { [wtppm] }\end{array}$ & $\begin{array}{l}\text { Average } \mathrm{E}_{\mathrm{acc}} \\
{[\mathrm{MV} / \mathrm{m}] / \mathrm{B}_{\mathrm{p}}[\mathrm{mT}]} \\
\text { before post- } \\
\text { purification }\end{array}$ & $\begin{array}{l}\text { Post } \\
\text { purification + } \\
100 \mu \mathrm{m} \mathrm{BCP} \\
\mathbf{E}_{\text {acc }}[\mathrm{MV} / \mathrm{m}]\end{array}$ & $\begin{array}{l}\text { "In-situ" baking } \\
\mathbf{E}_{\text {acc }}[\mathrm{MV} / \mathrm{m}]\end{array}$ & $\begin{array}{c}\text { "In-situ" baking } \\
\mathbf{Q}_{0} \text { at } \mathbf{E}_{\text {acc,max }}\end{array}$ \\
\hline 1164_12_12 & 1300 & $18.1 / 80$ & 29 & 29.6 & $9.4 \times 10^{9}$ \\
\hline 1164_11_14 & 1300 & $22.2 / 98$ & 24.8 & 27.2 & $8.9 \times 10^{9}$ \\
\hline 1161_31_34 & $\sim 150$ & $21.9 / 97$ & 27.8 & 26.5 & $6.4 \times 10^{9}$ \\
\hline 1161_32_33 & $\sim 150$ & $23.2 / 103$ & 27.3 & 33.5 & $7.5 \times 10^{9}$ \\
\hline 1162_33_34 & $\sim 600$ & $23.1 / 103$ & 31.5 & 35.9 & $15 \times 10^{9}$ \\
\hline 1162_32_35 & $\sim 600$ & $22.2 / 98$ & Not tested yet & Not tested yet & \\
\hline
\end{tabular}

